\title{
The Road to New Urbanization of Chang-Ji-Tu
}

\author{
Shujie $X u^{1, ~ a}$, Daqing Zhang ${ }^{2, b, *}$, and Laiwu Yin ${ }^{2, c}$ \\ ${ }^{1}$ Planned finance department, Jilin Agricultural Science and Technology College, Jilin, China \\ ${ }^{2}$ School of economic management, Jilin Agricultural Science and Technology College, Jilin, China \\ ${ }^{3}$ Network Information Center, Jilin Agricultural Science and Technology College, Jilin, China \\ a934853276@qq.com, bzdaq@qq.com, cyinlaiwu@163.com
}

Keywords: Chang-Ji-Tu, urbanization, industrial development

\begin{abstract}
Currently focused on developing their own industry development in Chang-Ji-Tu better township, make these areas first entered the threshold of the urbanization. Itself Chang-Ji-Tu the forefront of the region's economic development is in Jilin province, Chang-Ji-Tu Demonstration Town figure region accounted for nearly $50 \%$ of provincial, have the priority to the development of potential and resources. Demonstration Town industry development at present, there is still a layout is not standard, the problem such as unbalanced development, Jilin province constantly adjust, the industry development of Demonstration Town provide convenient conditions and resources. This paper analyzes the Chang-Ji-Tu region urbanization development way, hope to provide some reference for the development of other towns. To Chang-Ji-Tu area the same time some shallow Suggestions are put forward for further development of the urbanization, hope to Chang-Ji-Tu even in Jilin province urbanization development in the region to provide some reference value.
\end{abstract}

\section{Introduction}

The Chang-Ji-Tu plan has been released for nearly eight years, and the regional economy has made considerable progress, and has played a major role in promoting the province's economic development. New urbanization is the only way for modernization, and is the largest domestic demand potential and development momentum in China. It has become one of the important work of regional economic development [1]. Jilin province is based on regional characteristics in the development of urbanization, and actively explores the new road for urbanization in Jilin province. Chang-Ji-Tu area is the leading development area of Jilin Province, which plays a leading role in the development of new urbanization. At the same time, in the 22 demonstration towns of Jilin Province, Chang-Ji-Tu area occupies more than 10 . The economic development of Chang-Ji-Tu area is the best in the whole province, so it is positioned as a leading development area. The degree of economic development has promoted the development of urbanization to some extent. The role of economic development and the development of new urbanization can be roughly divided into two categories: one kind is one-way conduction, the other is two-way conduction. The one-way transmission role emphasizes the impetus of economic development to urbanization. It is considered that economic development is the fundamental motive force to promote the urbanization of villages and towns. With the continuous improvement of labor productivity and the increase of per capita income level, the output value and post occupation ratio of the second, third industry will increase with the output value of township and township. With the change of employment structure, the dividend brought by the rural population along with the economic development began to concentrate on urban areas, thus forming urbanization. The two way process considers that the two are not simple single conduction processes, but rather a rather complicated system function [2]. It is generally believed that the development of new urbanization is a systematic project in academic circles. Urbanization can also be counteracted to economic development in a certain degree to a certain extent. Both of them constitute the main theme of contemporary economic and social development. Therefore, the 
development of urbanization in Chang-Ji-Tu area will also play a role in the development of regional economy, and explore the road of urbanization in Chang-Ji-Tu area. On the one hand, it can serve as a reference for the development of the urbanization of Jilin Province, on the other hand, it also provides a way for the continuous development of Chang-Ji-Tu map region economy.

\section{The Development of Urbanization in Chang-Ji-Tu Area}

Since Chang-Ji-Tu area is the Pioneer Area of opening and opening up in 2009, with the further development of Chang-Ji-Tu map region economy, the urban and rural areas in Chang-Ji-Tu area revolve around "exploring the development path of integration of production city, exploring the construction mode of diversified investment, exploring effective methods of population urbanization and exploring the coordinated development of urban and urban development." To explore the institutional arrangement of solving the problem of urbanization "is the center of these five aspects. In the process of exploration, it is deeply recognized that urbanization is the urbanization of people, and the urbanization of people is the fundamental and essential. Industrialization is the means to drive the urbanization, promote the modernization of agriculture and ensure the urbanization, and the urbanization will also play a role in the development of industry and agriculture. Urbanization is a systematic project, which involves the factors of industry, agriculture and town. The relationship of support, integration and development is very close and complicated. It is of profound significance to explore the development path of urbanization in Chang-Ji-Tu area for the development of new urbanization in the whole province. The core of the new urbanization is "the urbanization of people", and this is deeply reflected in the development path of urbanization in Chang-Ji-Tu area. The urbanization in Chang-Ji-Tu area has taken a series of pragmatic measures to solve the "human problem" in the process of urbanization in the region, and the people's happiness index of Chang-Ji-Tu map is rising continuously [3].

In the town of Cha Lu River, "farmers bring into the city, take the mansion into the city, take the industry into the city and take advantage to the city", which fully safeguards the worries after the peasants enter the city and strengthens the employability of the new citizens in the process of urbanization, and the problem of embarrassment after the urbanization of the agricultural population has been effectively solved [4].

In accordance with the "project guidance, industrial support, three industry coordination, four chemical interaction, basic advance, service follow-up, whole staff launching, multiple coordination" work method, the ability of strengthening the industry, infrastructure and public service in the process of urbanization has provided a strong guarantee and support to the addition of new citizens. On the basis of urbanization, full play of the advantages of cities and towns to promote the development of agriculture in the direction of modernization, actively promote the integration of industry and agriculture, improve the carrying capacity of the city, and improve the sustainable development of agriculture and industry, and thus ensure the good and fast development of the city.

Helong town actively explores the path of "integration of production and urban integration, synchronization of four modernizations, interaction between urban and rural areas, and two-way development". Education and medical treatment first entered the process of urbanization, and the agricultural population was assisted by the medical and educational ability of Changchun. The development of urbanization from the future of the people, from the advance of education, the essence of the people-oriented thought is worth praising.

\section{The Development Road of Urbanization in Chang-Ji-Tu Area}

The development of urbanization in Chang-Ji-Tulu area is based on the human text and the development path of integration of production and city. The integration and development of production city is based on the premise, so the road integration road in Chang-Ji-Tu area needs to ensure the related industries in the urbanization area, and the industry needs a certain development prospect and competitive advantage. Urbanization is the product of economic development to a 
certain extent. Economic development can not be separated from the development of industry, and the integration and development of production city is the only way for the development of urbanization.

The integration of production and development focuses on planning, planning the key points of industrial development and the integration of regional development. Industrial development needs to be carried out in combination with regional advantages. On the one hand, factors such as geographical location, natural resources and human resources will restrict the development of industry. On the other hand, each region will have its own unique characteristics. If these characteristics can be developed into an industry, they will surely lead to regional economic development. The economy further drives the rural population into the industry and becomes the service provider of industrial workers or industries, and gradually gets rid of the identity of the farmers and is truly the urban population. The ratio of rural to urban areas will also change, and it will provide a way for the development of urbanization [5].

The Chang-Ji-Tulu area currently focuses on developing towns with better development of their own industries, so that these areas will first step into the threshold of urbanization. The economic development of Chang-Ji-Tu area is in the forefront of Jilin province. The demonstration town in Chang-Ji-Tu area accounts for nearly $50 \%$ of the province, and has the potential and resources for the development of the province. At present, the industrial development of the demonstration town still has the problems of irregular layout and unbalanced development. The Jilin province has constantly made adjustments to provide convenient conditions and resources for the industrial development of the demonstration town. In combination with the development needs of Chang-Ji-Tu map, Jilin province made an in-depth demonstration and investigation for the industrial layout of the demonstration town, and made important planning and deployment for the industrial agglomeration of the demonstration towns of Chang-Ji-Tu.

Secondly, the road of urbanization in Chang-Ji-Tu area is to strengthen the management and control mode with heavy planning, which can not be planned for the long term and sustainable development, and the urbanization must be built from the perspective of planning and overall strategy. In recent years, the Chang-Ji-Tu map area has completely strengthened the planning of urbanization, using the planning to command the development of urbanization, realizing the system engineering which combines planning with management and control, and guiding the new model of management and control. We should use planning to manage and control the construction of new towns and new towns, and realize the scientific demarcation of functional zoning. For example, the Jilin new China Food district and the Changchun Lotus Hill tourist resort are all engaged in professional planning by hiring experts. In the planning, we fully embody the advantages of the new area, carry out economic development according to local conditions, and support the pillar industries to promote the development of urbanization. The Lotus Hill tourist resort in Changchun has made full use of the local natural resource advantages. The new food area made full use of the local land resources and agricultural advantages, developed the corresponding brand tourism and brand agriculture, and created two new stars along the Chang-Ji-Tu map. The planning is far more than these. Further planning shows that the construction of the new areas in the two regions will lead to the economic development of the surrounding villages and towns, bring new sources of income for the local farmers, and also lay a solid foundation for the establishment of new towns in the center of the two new areas. In the construction of the new area, management and control have been strengthened under the planning. Special departments have been set up for the investment and investment of the new area, so as to encourage the relevant staff to introduce good capital, which greatly improves the efficiency and effect of the construction of the new area.

The other path of urbanization in Chang-Ji-Tu area is the urban development concept of "functional guidance development". Jilin province is a big agricultural province. Chang-Ji-Tu area is also a developed area of agriculture. In the process of urbanization development, it attaches great importance to the combination of regional characteristics and functions. We should focus on developing the regionalization features of cities and towns, and the development of special products to assist the construction of functional areas of the products. For example, the construction of the 
China and the new food area is to combine regional advantage products with rice, and to seek strong cooperation, and to cooperate with Singapore to establish the special function of the new area to assist the further development of the regional industry and the road of branding.

The development of urbanization has entered a new era, and the development of the new urbanization must also start from the solution of the fundamental contradictions in the new era. In the new period, the main contradictions in our society have been transformed into the contradiction between the growing and unbalanced development of the people and the uneven development of the people, and in the path of urbanization, we also We need to constantly explore the needs of good living for the townships and townships. The development of urbanization needs to be closely integrated with balanced and full development, and strive to realize the Chinese dream of a better life for rural residents at an early date.

\section{Suggestions on the Development of Urbanization in Chang-Ji-Tu Area}

The development of urbanization in Chang-Ji-Tu area is better in the key towns and towns. On the one hand, the economic foundation of these villages and towns is good, on the other hand, the obvious advantages of the region and the construction of the pilot area have brought new opportunities for the development of these towns. In the process of urbanization, the development of the key villages and towns plays a leading role. The purpose is to drive the process of urbanization in the whole region, and then promote the urbanization of the whole province. For this reason, the following suggestions are put forward for the future urbanization development in changjtu area [6].

\subsection{First, Consolidating the Existing Development and Taking a Foothold in the Long Run.}

At present, the urbanization of Chang-Ji-Tulu area has made certain achievements. Based on these achievements, we need to further consolidate the existing development results. Although the results have been achieved, the development of some key villages and towns is still in the stage of development and development, and it has not reached the stage of maturity. Therefore, it still needs to continue to develop and further expand the development results. Therefore, development can not be relaxed or slowed down. Instead, we need to further increase investment and support, laying a solid foundation for the development of urbanization in key towns. In the process of development, we need to pay attention to the combination of the Internet, because these growth network basic conditions are better, it is easy to combine with the Internet and have the advantages of some infrastructure. Increasing the development of Internet + is also a strategic choice based on long-term development. The Internet is the trend of the future development. The Internet of things is the mainstream of the future. The main industries that support the development of the urbanization of the key towns and towns need to combine with the Internet, and develop the integration with the Internet of things.

\subsection{Second, Green Development and Environmental Protection.}

The state has entered the stage of green ecological development. Therefore, in the development of urbanization in changjtu area, careful planning must be made for the choice of industries. In order to consider the long-term development of the region, we must choose to develop industries with low environmental destruction. The high pollution industry can not be introduced into the township development. At present, the city has already paid great attention to the environmental protection problem, and some enterprises with pollution are developing to the township. This trend also needs to be paid attention to in the development of urbanization in Chang-Ji-Tu area. For some highly polluting industries, it is necessary to light a red light, not only take into account the short-term development interests, but ignore the possibility of long-term development. In particular, in order to develop rapidly, in order to develop rapidly, the villages and towns are rapidly developing to the urbanization, ignoring the choice of industry and blindly introducing some highly polluting enterprises, which not only brings hidden dangers to the local long-term development, but also brings irreversible pollution to the local land, water resources and air, which affects the local residents. The quality of life makes it difficult for the local residents to live a better life. 


\subsection{Third, Strengthen the Radiation Effect and Promote the Development of the Surrounding Area.}

The development of urbanization in the key towns in Chang-Ji-Tu area has begun to take shape. These towns also need further development, but they can not ignore the support and support of other small and medium-sized towns. That is, the development of better cities and towns needs to be radiated to the two level and three level villages and towns, on the one hand, the expansion of the industrial scale can be expanded to these villages and towns, which can promote the development of the underdeveloped villages and towns, and further accelerate the speed of Urbanization in these areas. On the other hand, it is necessary to guide the development of the city's industry to the township, use the natural resources of the township to develop the industry, at the same time, it will help the development of towns and towns, develop the cities to the surrounding villages and towns, and develop the better towns and towns to promote the development of the surrounding villages and towns. This requires the support and guidance of the government policy, and also needs to plan the radiation development of the industry and bring the driving role of the town into full play.

\section{Summary}

In a comprehensive view, the development of urbanization in Chang-Ji-Tu area is a fast developing area in Jilin Province, but still exists the problem of unbalanced development. This paper analyzes the development road of urbanization in Chang-Ji-Tu area, and hopes to provide some reference for the development of other cities and towns. At the same time, some suggestions are made for the development of urbanization in Chang-Ji-Tu area, hoping to provide some reference value for the development of the urbanization of Chang-Ji-Tu, even in the urbanization of Jilin province.

\section{Acknowledgement}

Jilin Provincial Department of education "12th Five-Year" social science research project. (Project No: Ji Jiao Ke characters [2015] No. 299 ${ }^{\text {nd }}$ )

\section{References}

[1] Shujie Xu, Laiwu Yin. "Research on the development strategy of new urbanization in Changji area”, J. Journal of Jilin Agricultural Science and Technology College, Vol.25, No.4, pp. 29-31, December, 2016.

[2] Chunting Lang, Yangnan Yu. "Development status and Countermeasures of chang-ji-Tu development regional logistics”, Modern trade and industry, Vol.36, No.19, pp. 32-33, 2015.

[3] Tianxi Zhang, Tao Sun. "Research on local government innovation under Chang Ji Tu's regional development strategy - Analysis Based on the award project of 'local government innovation award' in China”, Northeast Asia Forum, Vol.4, pp. 92-97, 2013.

[4] Hui He, Chongzhi Bi. "Realistic opportunities and financial thinking of new urbanization in $\mathrm{Mu}$ Sui District”, Heilongjiang finance, Vol.3, pp. 32-34, 2014.

[5] Peng Yin, Cai Chen. "Research on the open economy development of Jilin province facing Northeast Asia Regional Cooperation”, Journal of Northeast Normal University (NATURAL SCIENCE EDITION), Vol. 47, No. 1, pp. 152-157, 2015.

[6] Yanduo Zhang. "Promoting the development of urban agglomeration and information integration in Northeast China”, Commercial economy, No. 8, pp. 26-28, 2015. 